\title{
Central Nervous System Ewing Sarcoma/Peripheral Primitive Neuroectodermal Tumor
}

National Cancer Institute

\section{Source}

National Cancer Institute. Central Nervous System Ewing Sarcoma/Peripheral Primitive Neuroectodermal Tumor. NCI Thesaurus. Code C129537.

A rare Ewing sarcoma/peripheral primitive neuroectodermal tumor that affects the central nervous system either as a primary dural neoplasm or by direct extension from adjacent soft tissues or bone. 